\title{
Students' perception of effective clinical teaching and teacher behaviour
}

\author{
Ijeoma L. Okoronkwo ${ }^{1 *}$, Jane-Lovena Onyia-Pat ${ }^{1}$, Mary-Ann E. Agbo ${ }^{1}$, Pat U. Okpala ${ }^{1}$, \\ Afam C. $\mathrm{Ndu}^{1,2}$ \\ ${ }^{1}$ Department of Nursing Sciences, University of Nigeria, Enugu Campus, Enugu, Nigeria \\ ${ }^{2}$ Post Basic School of Psychiatric Nursing, Federal Neuropsychiatric Hospital, Enugu, Nigeria \\ Email: ĳeoma.okoronkwo@unn.edu.ng, Onyia400@yahoo.com, ogelinks2006@yahoo.com, favouredpat4@yahoo.com
}

Received 23 January 2013; revised 25 February 2013; accepted 3 March 2013

\section{ABSTRACT}

Learning in the clinical environment is an integral part of nursing education programme. In tertiarybased nursing courses, students spend time learning in the clinical setting as they do in their classroombased studies. The purpose of this study was to explore teaching skills considered by undergraduate student nurses as effective in the clinical setting as well as qualities that make a clinical teacher effective. A descriptive design was employed using questionnaires to collect data. Respondents comprised year four undergraduate student nurses admitted through direct entry (DE) and university matriculation examination (UME) results. Using validated structured questionnaire, data were collected from 101 students who had completed their six months consolidated clinical experience on their perception of teaching skills and teacher qualities considered effective in the clinical setting. Data were analyzed using both descriptive and inferential statistics. Specifically, frequencies, percentage and standard deviation were used for descriptive analysis of scores while chi square and Mann-Whitney tests were used to test the mean differences in the teaching skills and to test whether there was a significant difference in their perception of teacher behaviours respectively at 0.05 level of significance. The result showed that having both clinical (professional) and teaching knowledge were the most important teaching skills for effective clinical teaching. Five qualities ranked by students as teacher behaviours important for effective teaching include being honest with students, motivation to teach, willingness to listen and using good communication skills, supervising students effectively and being positive role model. These factors could be considered when recruiting future clinical teachers and when planning in-service education programmes for

${ }^{*}$ Corresponding author. clinical teachers to promote student learning.

Keywords: Clinical Teaching in Nursing; Direct Entry and University Matriculation Examination Students; Student Nurses' Perceptions; Teachers' Behaviours

\section{INTRODUCTION}

In virtually all countries nurses constitute the largest health care provider group and the International Council of Nurses (ICN) 2000 reports that 11 million nurses practice around the world [1]. Effective clinical teaching is critical for students' learning in the clinical setting [2,3]. This is because clinical teaching helps to prepare students for the work they will have to do as practicing nurses. Furthermore, clinical experience allows student nurses to participate actively in the healthcare team, seek solutions to real life problems and learn by doing while caring for patients thereby becoming competent practitioners [4]. A poorly trained nurse might hamper the team's effectiveness leading to ineffective nursing care. Studies have shown that effective clinical teacher behaviours promote effective clinical teaching which in-turn enhance students' learning process [3,5]. Effective clinical teaching is critical for producing knowledgeable and skilful nurses who can deliver safe quality nursing services to individuals, families and communities.

Clinical teaching according to the work of [6] is a set of planned experiences designed to help students acquire skills, attitudes and knowledge by participating in the work setting. Schö̈nwetter et al. [7] are of the opinion that in the clinic, theory is put into practice and the qualities focus more on the psychomotor (giving bed bath, medication) and affective abilities (listening to patients) as compared to cognitive abilities used often in the classroom. These qualities are critical for student learning especially in professional fields such as nursing, medicine and dentistry. However, reference [7] has observed that these professions are often taught by expert 
clinicians who for the most part, have limited or no prior teaching training. In addition, Allison-Jones and Hirt [8] have observed that experienced faculty available for clinical teaching in these fields are diminishing and many clinical teachers are employed casually. Poor clinical teacher preparation is therefore seen as a common problem to effective clinical teaching. These among others have resulted in the gap existing in nursing theory and practice [9].

Researchers have investigated into effective clinical teaching in various fields. In the study of students' perceptions of effective classroom and clinical teaching in Dental and Dental Hygiene education, [7] reported that individual rapport was the most effective clinical teacher behaviour. According to them, rapport in a clinical setting involves a closer physical proximity of instructor to student and much smaller and potentially intimate teacher-to-student ratio. Similarly Fugill [10] in his study on teaching and learning in dental student clinical practice identified professional competence, approachable personality and availability of teacher as desirable clinical teacher behaviours for the third and fourth year dental students. In medicine, reference [4] reported lack of clear expectations for student performance, inadequate feedback, and inappropriate role models as glaring problems of effective clinical teaching. In nursing, Kelly [11] identified teacher knowledge, giving timely feedback, ability to listen to students and availability of teacher as effective clinical teacher characteristics. Despite the importance of clinical teaching to the nursing profession, in multiple settings, Nigeria inclusive, student nurses are often taught by clinical instructors who have little or no prior formal teaching $[7,12]$. Other researchers have observed that there are no guidelines to assist clinical teachers on how to effectively teach and supervise students in the clinical area $[2,4]$.

In Nigeria, students are admitted into the university based nursing programme through two modes-direct entry (DE) and university matriculation examination (UME) result. In addition to other nursing practicum in their programme, students are expected to complete a six month consolidated clinical experience in an affiliated teaching hospital where they rotate within different specialties. Feedback received after these clinical experiences buttress the fact that there is a gap between what is learnt in classroom and that received in the clinical area in addition to inadequate guidance and supervision. To narrow this gap, there is need for effective clinical teaching of would-be nurses.

Different methodologies like peer, self and student evaluation have been used to investigate into effective clinical teaching and clinical teacher effectiveness [11, 12]. Current procedures used in evaluating teaching in health related fields, are generally student based. Al- though peer and self evaluation are in use, universities have tended to rely primarily on students' evaluation when trying to quantify an instructor's teaching effectiveness [13]. Many of these studies were done in developed countries. No published study could be identified as criteria to determine teaching skills considered effective for clinical teaching and characteristics of effective clinical teacher in Nigeria generally and the study area in particular. Considering that effective clinical teaching is vital for quality nursing practice and that student experiences of their clinical practice provide greater insight to developing an effective clinical teaching strategy, the authors decided to explore students' views based on what other studies have done.

\subsection{Purpose}

The purpose of the study was to explore teaching skills considered by undergraduate student nurses as effective in the clinical setting. Specifically the research objectives were to ascertain the views of undergraduate students on teaching skills considered effective for clinical teaching; identify five characteristics of teacher behaviours deemed most important for teaching in the clinical setting and compare the views of DE and UME students on teaching skills and teacher behaviours for effective clinical teaching.

\subsection{Definition of Terms}

For the purpose of this study, the following concepts were defined operationally.

Direct entry student refers to a student who is a registered nurse and is admitted through direct entry admission to pursue a degree in nursing.

Effective clinical teaching refers to the ability of the clinical teacher to apply different types of knowledge to enhance students learning. The knowledge could be both teaching and professional, pedagogical, general, or political knowledge.

Students' perception refers to views or opinions of students on teaching skills and teacher behaviour.

Teacher behaviour refers to those qualities or characteristics of the teacher that facilitate student learning.

Pedagogical knowledge refers to ability of clinical teachers to utilize a broad range of teaching methods to convey information to students.

University matriculation examination student refers to a student who is fresh from the secondary school and has passed the UME and is admitted into year one to pursue a degree in nursing.

\section{METHOD}

This non-experimental quantitative descriptive study was 
conducted in the Department Nursing Sciences of the University of Nigeria, Enugu state, Nigeria using questionnaire.

\subsection{Participants}

All the 400 level undergraduate nursing students who had completed their six months consolidated clinical experience participated in the study.

\subsection{Data Collection}

The only instrument for data collection was the questionnaire developed by the researchers. The questionnaires were divided into parts. Part 1 consisted of background information of respondents, part two had eight items (teaching skills) for determining effective clinical teaching while part 3 consisted of 15 items (teacher behaviour) for clinical teacher effectiveness with a four point rating scale ranging from strongly agree to strongly disagree. The teaching skills and qualities were drawn from literature reviewed. Both face and content validity of the questionnaire were ensured by the critical scrutiny of experts in nurse education and measurement and evaluation. The reliability of the instrument was ascertained using a test retest method at interval of two weeks among 10 undergraduate nurses from another institution that was not part of the study. Data obtained were computed using Pearson Product Moment correlation co-efficient formula. A co-efficient reliability of 0.8 was obtained confirming an acceptable level of reliability. Corrections made were used to modify the final instrument. The instrument was administered to the students during break periods to avoid interference with lectures. The students' class list was used by the researchers to ensure consistency and that no student was missed out. Data collection lasted for a period of five days and all the one hundred and one questionnaire were completely filled and returned.

\subsection{Ethical Consideration}

An institutional permission was obtained to carry out the study while informed consent was obtained from the participants. The students were informed that participation to the study was voluntary and anonymity ensured. They were also informed about the purpose of the study and that they could withdraw at any time from the study if they felt uncomfortable about it.

\subsection{Data Analysis}

Data were entered into the Statistical Package for Social Sciences (SPSS) version 17.0. Data from parts 1 and 2 (demographic characteristics and teaching skills) were analysed using frequencies and percentages. Any score above $60 \%$ was considered being effective for the teaching skills. A 4 point rating scale of strongly agree to strongly disagree was used to rank qualities perceived to be effective teacher behaviours in clinical teaching. Chisquare statistics was used to determine whether the means of perceived teaching skills were significantly different by mode of admission while Mann Whitney test was used to test whether there was a significant difference in their perception of teacher behaviours at 0.05 level of significance. Mann Whitney test is a test designed to test the significance difference between two populations.

\section{RESULTS}

Out of the 101 respondents, 40 were direct entry (DE) students while 61 students were admitted through the University matriculation examinations (UME). The DE students are students who already possess their Registered Nurse $(\mathrm{RN})$ certificates and are admitted in the second year of the BNSc degree programme while the university matriculation examination (UME) result students otherwise known as generic students are admitted fresh from secondary schools into the programme.

\section{Demographic Information}

The ages of the students ranged from $>20$ years to 40 and above with a mean age of 26.2 years (DE 30.3) years while $(\mathrm{UME}=23.6)$ year (Table 1). Out of the $40 \mathrm{DE}$ students, none was below age 20 , half of the students 20 $(50 \%)$ were between 25 - 29 years of age, $11(22.5 \%)$ were aged $30-34$ years, $4(10 \%)$ fell within the age range of 35 - 39 years while $3(7.5 \%)$ were aged 40 years and above.

On the other hand, out of the 61 UME students 3 $(4.9 \%)$ were below the age of 20 years. More than half $38(62.3 \%)$ were between 20 - 24 years old, $18(29.5 \%)$ were aged 25 - 29 years, $2(3.3 \%)$ fell within the age range of $30-34$ years while none of the UME students was within the age group of 35 - 39 and 40 and above years respectively.

From the result, more females were admitted in the direct entry programme than males. Out of the $40 \mathrm{DE}$ students $35(97.5 \%)$ were females while $5(12.5 \%)$ were males. In fact for every one male student admitted there were seven females. Similarly, there was a preponderance of female students admitted through the UME programme. Out of 61 students $54(88.5 \%)$ were females while $7(11.5 \%)$ were males.

From Table 2, out of the eight teaching skills used in determining what constitute effective clinical teaching, four met the decision criterion of ( $60 \%$ and above). They include having both clinical (professional) and teaching knowledge (96\%), pedagogical knowledge (71.3\%), 
knowledge of content or subject matter $(69.3 \%)$ and general knowledge (63.4\%). The chi square statistics showed that the two groups of student did not differ in their opinion on the variables that constitute clinical teaching $p>0.05$ with the exception of knowledge of content and having clinical knowledge only which were statistically significant $(\mathrm{p}=0.006<0.05 ; \mathrm{p}=0.014<0.05$ respectively).

From Table 3, respondents were asked to rank five teacher behaviours considered most important in the clinical setting from a list of 15 items. Surprisingly, the two groups of students identified the same factors though different in order of ranking. They include honesty, motivation to teach, listening and good communication skill, good supervision and positive role model in that order. While UME students ranked honesty as number one factor with $(\mathrm{X}=3.84$; $\mathrm{SD}=0.37)$; DE students ranked motivation to teach $(\mathrm{X}=3.80 ; \mathrm{SD}=0.46)$ as the most important characteristics. Listening and communication skill was ranked second by UME students $(\mathrm{X}=3.77$; SD $=0.49)$ while DE students ranked it as number three factor $(\mathrm{X}=3.75$; $\mathrm{SD}=0.59)$.

The above qualities were further subjected to Mann Whitney test to identify differences in perception by mode of admission. Findings showed that there was no significant difference in their perception with the exception of giving constructive feedback $(p=0.046<0.05)$ which showed a significant difference.

\section{DISCUSSION}

\subsection{Perception of Students on Effective Clinical Teaching}

Both clinical (professional) and teaching knowledge were seen as the most important teaching skill for effective clinical teaching in this study. A review of literature shows that the best clinical teachers are clinically competent and have teaching knowledge [3,14]. The finding of this study is supported by the works of other researchers $[6,11]$ who reported that clinical instruction involves relating classroom teaching to clinical practice and identified professional knowledge as a characteristic of an effective clinical teacher. Similarly in a study on "determinants of effective clinical learning: a student and teacher perspective in Saudi Arabia", students perceived

Table 1. Demographic characteristics of respondents and mode of admission.

\begin{tabular}{cccc}
\hline Sex & Direct Entry (DE) & (UME) & Total \\
\hline Male & $5(12.5 \%)$ & $7(11.5 \%)$ & $12(11.9 \%)$ \\
Female & $35(87.5 \%)$ & $54(88.5 \%)$ & $89(88.1 \%)$ \\
Total & $40(100 \%)$ & $61(100 \%)$ & $101(100 \%)$ \\
\hline \multirow{4}{*}{ Age (Years) } & \multicolumn{3}{c}{ Mode of Admission } \\
\cline { 2 - 4 }$>20$ yrs & $0(0 \%)$ & $3(4.9)$ & $3(3.0 \%)$ \\
$20-24$ yrs & $2(5.0 \%)$ & $38(62.3 \%)$ & $40(39.6 \%)$ \\
$25-29$ yrs & $20(50 \%)$ & $18(29.5 \%)$ & $38(37.6 \%)$ \\
$30-34$ yrs & $11(27.5 \%)$ & $2(3.3 \%)$ & $13(12.9 \%)$ \\
$35-39$ yrs & $4(10.0 \%)$ & $0(0 \%)$ & $4(4.0 \%)$ \\
$40 \&$ above & $3(7.5 \%)$ & $0(0 \%)$ & $3(3.0 \%)$ \\
Total & $40(100 \%)$ & $61(100.0 \%)$ & $101(100.0 \%)$ \\
\hline
\end{tabular}

N/B: DE = Direct entry; UME = University matriculation examination.

Table 2. Students' perceptions of teaching skills for effective clinical teaching.

\begin{tabular}{|c|c|c|c|c|}
\hline Items & Direct entry (DE) $n=40$ & $(\mathrm{UME}) \mathrm{n}=61$ & Total $\mathrm{n}=101$ & p-value significance ${ }^{*}$ \\
\hline Both clinical and teaching knowledge & $\begin{array}{c}\text { Yes } 40(100 \%) \\
\text { No } 0(0 \%)\end{array}$ & $\begin{array}{c}57(93.4 \%) \\
4(6.6 \%)\end{array}$ & $\begin{array}{c}97(96.0 \%) \\
4(4.0 \%)\end{array}$ & $\begin{array}{c}\mathrm{p}=0.098 \\
\mathrm{p}>0.05\end{array}$ \\
\hline Having pedagogical knowledge & $\begin{array}{c}\text { Yes } 30(75 \%) \\
\text { No } 10(25.0 \%)\end{array}$ & $\begin{array}{l}42(68.9 \%) \\
19(31.1 \%)\end{array}$ & $\begin{array}{l}72(71.3 \%) \\
29(28.7 \%)\end{array}$ & $\begin{array}{c}p=0.504 \\
p>0.05\end{array}$ \\
\hline Knowledge of the subject matter (content) & $\begin{array}{c}\text { Yes } 34(85 \%) \\
\text { No } 6(15 \%)\end{array}$ & $\begin{array}{l}36(59.0 \%) \\
25(41.0 \%)\end{array}$ & $\begin{array}{l}70(69.3 \%) \\
31(30.7 \%)\end{array}$ & $\begin{array}{c}\mathrm{p}=0.006^{*} \\
\mathrm{p}<0.05\end{array}$ \\
\hline Knowledge of learner & $\begin{array}{l}\text { Yes } 23(57.5 \%) \\
\text { No } 17(42.5 \%)\end{array}$ & $\begin{array}{l}32(52.5 \%) \\
29(47.5 \%)\end{array}$ & $\begin{array}{l}55(54.5 \%) \\
46(45.5 \%)\end{array}$ & $\begin{array}{c}\mathrm{p}=0.619 \\
\mathrm{p}>0.05\end{array}$ \\
\hline Clinical knowledge only & $\begin{array}{l}\text { Yes } 27(67.5 \%) \\
\text { No } 13(32.5 \%)\end{array}$ & $\begin{array}{l}26(42.6 \%) \\
35(57.4 \%)\end{array}$ & $\begin{array}{l}53(52.5 \%) \\
48(47.5 \%)\end{array}$ & $\begin{array}{c}\mathrm{p}=0.014^{*} \\
\mathrm{p}<0.05\end{array}$ \\
\hline General knowledge & $\begin{array}{c}\text { Yes } 28(70 \%) \\
\text { No } 12(30.0 \%)\end{array}$ & $\begin{array}{l}36(59.0 \%) \\
25(41.0 \%)\end{array}$ & $\begin{array}{l}64(63.4 \%) \\
37(36.6 \%)\end{array}$ & $\begin{array}{c}\mathrm{p}=0.263 \\
\mathrm{p}>0.05\end{array}$ \\
\hline Political knowledge & $\begin{array}{c}3(7.5 \%) \\
37(92.5 \%)\end{array}$ & $\begin{array}{c}5(8.2 \%) \\
56(91.8 \%)\end{array}$ & $\begin{array}{c}8(7.9 \%) \\
93(92.1 \%)\end{array}$ & $\begin{array}{c}\mathrm{p}=0.899 \\
\mathrm{p}>0.05\end{array}$ \\
\hline
\end{tabular}

${ }^{*}$ p-value significant at 0.05 level. 
Table 3. Ranking of clinical teacher behaviour by mode of admission as perceived by students.

\begin{tabular}{cccccc}
\hline \multirow{2}{*}{ Qualities } & \multicolumn{2}{c}{ DE } & \multicolumn{2}{c}{ UME } & p-Value \\
\cline { 2 - 5 } & $\mathrm{X}$ & $\mathrm{SD}$ & $\mathrm{X}$ & $\mathrm{SD}$ & \\
\hline Positive role model & 3.65 & 0.62 & 3.64 & 0.66 & 0.982 \\
Flexibility & 3.28 & 0.79 & 3.39 & 0.82 & 0.328 \\
Motivation to teach & 3.80 & 0.46 & 3.74 & 0.48 & 0.424 \\
Authoritativeness & 1.43 & 0.71 & 1.41 & 0.56 & 0.734 \\
Empathetic & 2.70 & 0.10 & 2.64 & 0.98 & 0.725 \\
Calmness & 3.53 & 0.78 & 3.56 & 0.65 & 0.878 \\
Listening & 3.75 & 0.59 & 3.77 & 0.49 & 0.976 \\
Encouraging mutual respect & 3.68 & 0.53 & 3.56 & 0.67 & 0.463 \\
Giving constructive \& timely feedback & 3.63 & 0.63 & 3.39 & 0.67 & $0.046^{*}$ \\
Building confidence \& trust & 3.35 & 0.66 & 3.41 & 0.61 & 0.693 \\
Honesty & 3.78 & 0.58 & 3.84 & 0.37 & 0.843 \\
Availability of teacher in clinical settings & 3.60 & 0.90 & 3.62 & 0.66 & 0.449 \\
Less student-teacher ratio & 3.63 & 0.59 & 3.61 & 0.56 & 0.773 \\
Supportive work environment & 3.60 & 0.71 & 3.44 & 0.62 & 0.093 \\
Supervision of students & 3.68 & 0.62 & 3.67 & 0.57 & 0.736 \\
\hline
\end{tabular}

"p-value significant at 0.05 level.

that supervisors should have certain teaching skills to facilitate students' learning in the clinical environment [15]. It can be deduced from these findings that without clinical and teaching knowledge, no clinical teacher can be truly effective. The implication is that a clinical teacher or instructor must possess both theoretical and practical knowledge in addition to having teaching experience in order to prepare competent student nurses.

Other factors that met the study criteria like having pedagogical knowledge (71.3\%), knowledge of the subject matter $(69.3 \%)$ and general knowledge $(63.4 \%)$ have also been identified from review of literature as constituting effective clinical teaching [11]. A comparison of the mean perceptions by mode of admission on the teaching skills for effective clinical teaching showed that there was no significant difference $p>0.05$ with the exception of knowledge of the subject matter and having clinical knowledge only $(\mathrm{p}=0.006<0.05 ; \mathrm{p}=0.014<$ 0.05 ) respectively which were significantly different. DE students were more likely to cite these two factors as constituting effective clinical teaching than UME students.

\subsection{Characteristics of Effective Clinical Teachers}

Clinical teacher behaviour perceived by dental students to be effective in their study were similar to those identified in this study. Both DE and UME students were of the view that the five most important teacher behaviours should include honesty, motivation to teach, listening and good communication skills, good supervision and good role model in that order. This finding is in line with other research studies. Many authors have stressed the importance of being honest with students and providing constructive feedback for effective clinical teaching [6, 14]. Being honest with students helps to build confidence and trust. Effective instructors provide appropriate and usable feedback to students about their clinical performance. They give specific and constructive feedback about performance and are knowledgeable about what students need to know and the criteria for acceptable performance. However, this finding is not in agreement with the findings of [7] where rapport was observed to be the most effective teaching behaviour.

Research on effective teaching skills points out that, aside from professional knowledge, a good tutor needs to possess positive personality traits [16]. Personality quailties identified by the study participants for teacher effectiveness in a clinical setting include having the motive to teach and being a good role model. These factors have been supported by other researchers $[7,14]$ as qualities to be possessed by effective clinical teachers. These authors 
agree that positive role model is critical for effective clinical teaching and that clinical teachers who are good role models for students enjoy teaching, are well prepared for teaching, stimulate students' interests, explain concepts and procedures clearly and supervise students effectively. This finding suggests that in addition to knowledge and skills, the personality of a lecturer plays an important role in the learning process. Exposing students to excellent role models inspires them to study better. According to [17] the personality of a lecturer can have a strong effect on the behaviour and attitude of his students. The implication of this finding is that clinical teachers should pay more attention to their characteristics if quality of their teaching is to be improved.

Listening ability and good communication skills were ranked third as teacher behaviour in clinical teaching. This finding is supported by reference [11] that having listening ability, and being calm are desirable clinical teacher behaviour for clinical teaching. Communication skills create positive learning environment for students.

Supervision of students was ranked fourth by both groups as important teacher behaviour in clinical teaching. Reference [9] in their study on nursing student experiences of clinical practice considered supervision as an important clinical experience. According to the work of [18] if students are to acquire knowledge of and skills in clinical practice, someone must be there to supervise and demonstrate how theoretical knowledge can be integrated into practice. Clinical supervision of students is a powerful way of enabling students realize desirable practice. There was significant difference in the perception of the two groups of students in providing constructive and timely feedback $(p=0.046<0.05)$ with DE students being more likely to cite it than UME students. This may be attributed to the fact that DE students are already trained and registered nurses with experience and understand the importance of timely feedback to avert costly mistakes on patient's life.

\section{CONCLUSION}

The findings of this study confirm results from similar studies in the developed countries that effective clinical teaching requires knowledgeable and competent instructors who are able to communicate that knowledge to students. Qualities identified by undergraduate student nurses as most important for teacher effectiveness in the clinical setting should be considered when employing clinical teachers in the clinical area to promote effective learning.

\section{RECOMMENDATIONS}

Given the special challenges of clinical nursing education, it is recommended that:
Graduate programmes should seek to teach skills identified as most effective and persons with skills perceived as effective should be recruited as clinical teachers.

Theory practice gap should be bridged through supervision of students in the clinical setting as it has been identified as important teacher behaviour in clinical teaching.

Workshops/seminars should be organised for would be clinical teachers on their roles in clinical teaching.

Clinical teachers should possess both clinical and teaching knowledge for effectiveness.

The results of this study should be complemented by a study performed in a larger population also exploring teachers' views.

\section{LIMITATIONS}

Our study has some limitations. Relying on only subjective assessments and personal views cannot confirm or quantify the impact of each factor identified. Further studies using other, complementary study approaches should assess the impact of the factors identified in this study. The study findings cannot be generalized to other Department of Nursing in Nigeria.

\section{ACKNOWLEDGEMENTS}

We thank all the students who participated in this study. We also express our gratitude to the Head of Department for supporting this research.

\section{REFERENCES}

[1] Pearson, A. and Peels, S. (2008) Nursing-A global perspective. International Journal of Nursing Practice. http://onlinelibrary.wiley.com/doi/10.1046/j.1440-172x

[2] Eta, V.E.A., Atanga, M.B.S., Atashili, J. and D'Cruz, G. (2011) Nurses and challenges faced as clinical educators: A survey of a group of nurses in Cameroon. The Pan African Medical Journal, 8, 28. doi:10.4314/pamj.v8i1.71085

[3] Tamara, L., Buchel, T.L. and Edwards, F.D. (2005) Characteristics of effective clinical teachers. Family Medicine, 37, 30-35.

[4] Irby, D.M. (2007) Effective clinical teaching and learning: Clinical teaching and the clinical teacher. http://www.med.cmu.ac.th/ssecret/meded/ct2.htm

[5] Levy, L.S., Sexton, P., Willeford, K.S., Barnaum, M.G., Guyer, M.S., Gardner, G. and Fincher, A.L. (2009) Clinical instructor characteristics, behaviours and skills in allied healthcare settings: A literature review. Athletic Training Educational Journal, 4, 8-13.

[6] Steves, A.M. (2005) Improving the clinical instruction of student technologists. Journal of Nuclear Medicine Technology, 33, 205-209.

[7] Schö̀nwetter, D.J., Lavigne, S., Masurat, R. and Nazarko, 
O. (2006) Students' perception of effective classroom and clinical teaching in dental and dental hygiene education. Journal of Dental Education, 70, 624-635.

[8] Allison-Jones, L.L. and Hirt, J.B. (2004) Comparing the teaching effectiveness of part time \& full time clinical nurse faculty. Nursing Education: Perspectives, 25, 238243.

[9] Sharif, F. and Masoumi, S. (2005) A qualitative study of nursing student experiences of clinical practice. BioMed Central Nursing, 4, 6. doi:10.1186/1472-6955-4-6

[10] Fugill, M. (2005) Teaching and learning in dental student clinical practice. European Journal of Dental Education, 9, 131-136. doi:10.1111/j.1600-0579.2005.00378.x

[11] Kelly, C. (2007) Students' perceptions of effective clinical teaching revisited. Nurse Education Today, 27, 885892. doi:10.1016/i.nedt.2006.12.005

[12] Lee, C., Cholowski, K. and Williams, A.K. (2002) Nursing students' \& clinical educators' perceptions of characteristics of effective clinical educators in an Australian school of nursing. Journal of Advanced Nursing, 39, 412511. doi:10.1046/j.1365-2648.2002.02306.x

[13] Hobach S.M and Talbot, D.M. (2001) Understanding students' evaluations. College Teaching, 49, 7555-8756.

[14] Talwar, D.S. and Weilin, S. (2005) Qualities of an effective teacher: The dental faculty perspective. Journal of Dental Education, 69, 116.

[15] AlHaqwi, A.L., van der Molen, H.T., Schmidt, H.G. and Magzoub, M.E. (2010) Determinants of effective clinical learning: A student and teacher perspective in Saudi Arabia. Education for Health, 23, 369. http://www.educationforhealth.net/

[16] Martens, M.J.C., Duvivier, R.B., Dalen, J.V., Maarten, G., Verwijnen, G.M., Scherpbier, A.J.J.A. and Vleuten, C.P.M. (2009) Student views on the effective teaching of physical examination skills: A qualitative study. Medical Education, 43, 184-191. doi:10.1111/j.1365-2923.2008.03283.x

[17] Gillespie, M. (2002) Student-teacher connection in clinical nursing education. Journal of Advanced Nursing, 37, 566-576. doi:10.1046/j.1365-2648.2002.02131.x

[18] Lambert, V. and Glacken, M. (2005) Clinical education facilitators: A literature review. Journal of Clinical Nursing, 14, 664-673. doi:10.1111/j.1365-2702.2005.01136.x 


\section{QUESTIONNAIRE}

Dear Respondent

This questionnaire is designed to obtain information on students' Perception of effective clinical teaching and teacher behaviour.

This research work is purely for academic purposes and every information supplied will be treated in confidence. Do not write your name.

Thank you for your expected co-operation.

\section{Instructions}

Answer the questions in section A as appropriate.

\section{Section A}

1) Sex:

Female [ ] Male [ ]

2) Age in years:

a) $>20$ [ ] b) $20-24$ [ ] c) $25-29$ [ ]

d) $30-34[$ ] e) $35-39[$ ] f) 40 and above [ ]

3) Mode of admission:

a) Direct entry [ ] b) UME [ ]

\section{Section B}

Answer the questions in section B as appropriate. Tick $(\sqrt{ })$ at the column that represent your opinion against the statement in section B.

\section{Teaching Skills for Effective Clinical Teaching}

4) Having both clinical and teaching knowledge Yes [ ] No [ ]

5) Having pedagogical knowledge

Yes [ ] No [ ]

6) Knowledge of subject matter

Yes [ ] No [ ]

7) Knowledge of the learner

Yes [ ] No [ ]

8) Having clinical knowledge only

\author{
Yes [ ] No [ ] \\ 9) General knowledge \\ Yes [ ] No [ ] \\ 10) Knowledge of self \\ Yes [ ] No [ ] \\ 11) Political knowledge \\ Yes [ ] No [ ]
}

\section{Section C}

Answer the questions in section $\mathrm{C}$ as appropriate. Tick $(\sqrt{ })$ at the column that represent your opinion against the statement.

For example, If you "strongly agree", tick "SA"; If you "agree" tick "A"; If you "strongly disagree" tick "SD" and If you "disagree" tick "D".

Teacher Behaviour (Qualities) Considered Important for Effective Clinical Teaching SA A D SD

12) Positive role model

13) Flexibility

14) Motivation to teach

15) Authoritativeness

16) Empathetic

17) Calmness

18) Listening

19) Encouraging mutual respect

20) Giving constructive and timely feedback

21) Building confidence and trust

22) Honesty

23) Availability of teacher in clinical settings

24) Less student-teacher ratio

25) Supportive work environment

26) Supervision of students 